\title{
دور العلاقات العامة فى تسويق الأحداث والبطولات الرياضية داخل الأندية
}

\section{الرياضية بدولة الكويت}

* د/ دلال نايف مبارك الحجرف

مقدمة البحث:

نظـراً لأهميـة الأنديـة الرياضـية والـدور الذـى تلعبـه في المجتمع ولأهميـة الأحـداث والبطـولات

الرياضـية واهتمـام الشـباب والـنشع بـالبطولات الرياضـية سـواء ذلك بالمشـاركة أو بالمشـاهدة وحضـور المباريات والبطولات الرياضية فى العصر الحديث والأزدياد المتواصل فى الحاجة إليها. أن تسويق الأحداث والبطولات الرياضية داخل الأندية الرياضية لما تدره من أموال على الأندية الرياضية أصبح أمراً هاماً ويجب إداراته بالأساليب والطرق العمية الحديثة.

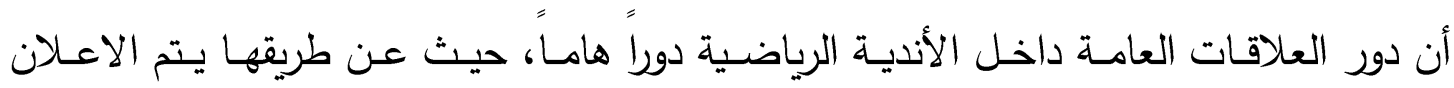
والاعلام والتعريف بالأندية الرياضية والأنشطة التى تقوم بها الأندية الرياضية وما تقدمه للمجتمع.

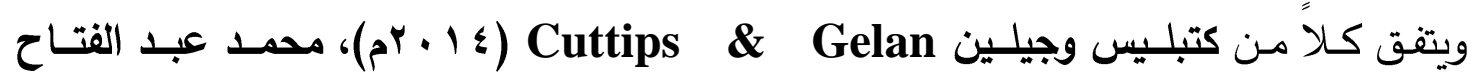
(7 ا • r م) أن يثمل التخطيط الاستراتيجي للعلاقات العامة التبؤُ بالحالة المرغوب فيها مستقبلاً وكذلك تحديد العوامل أو المتغيرات التي تساعد في تحقيق هذا الوضع المستقبلي أو التي قد تحول دون تحقيق هذا الوضـع، والمؤسسـات التي لا تعتمد على عملية التخطيط الاستراتيجي تواجه صـوبات ومشكلات عديدة مثل سوء الفهم عن المؤسسة وما تقدمه من أنثطة وخدمات.

$(1 \mu 1: 1 \cdot) \cdot(r \leqslant 0: 11)$

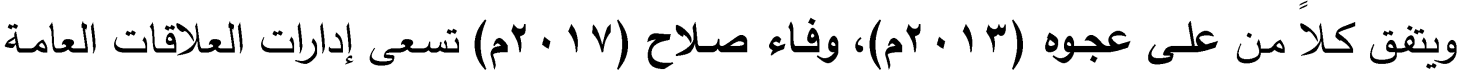

بمختلف المنظمات الأهلية والحكومية إلى التكامل مع عملية التخطيط لتتسق مع خطة المنظمة، أى أنها تستوعب الأهداف الاستراتيجية للمنظمـة ثم تعيد تشكيلها فى إطـار العلاقات العامـة. (1: ب ا)، (0 :

تعتبر الأندية الرياضية أحد الميادين الرياضية الهامة التى تقدم العديد من الخدمات

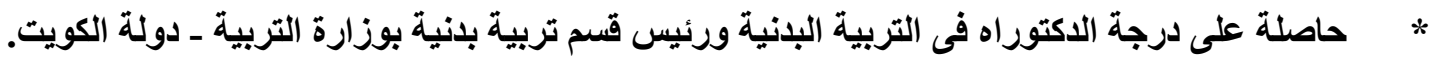




\section{ISSN : YVYัO-\{}

لجمهورها فى صورة أنشطة رياضية واجتماعية وثقافية وإقامة المنافسات والبطولات الرياضية والمشاركة فيها وهذا لن يتأتى إلا فى ظل وجود إدارة للعلاقات العامـة متخصصـة يتت عن طريقها إيجاد نوع من التنسيق بين هذه الأنثطة حتى يمكنها تحقيق أهدافها.

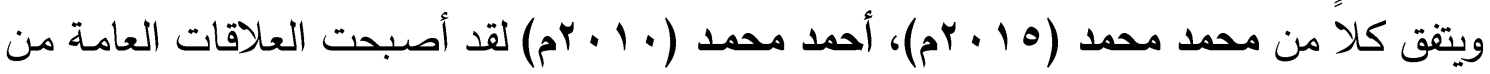
خلال وظائفها وأنشطتها أحد المنظومات الهامة التى تساعد الإدارة فى المؤسسات المختلفة حتى تكون على اتصـال دائم مـع الجماهير فى الداخل والخـارج مدا يعمل على تحسين قرارتها وتصـيح مسارها. $(V: 1) \cdot(9: 11)$ ويرى برونسون Bronson (0 1 • r م) لا يمكن لأى مؤسسة رياضية أن تتمتع بفترة طويلة من النجاح والاستقرار بدون دعم ومسـاندة جماهيرهـا مـن خـلال مـا تقوم بـه العلاقـات العامـة نحو توطيد العلاقات الطيبة المتمثلة بالثقة ما بين تلك الجماهير وإدارة المؤسسة الرياضية. (V)

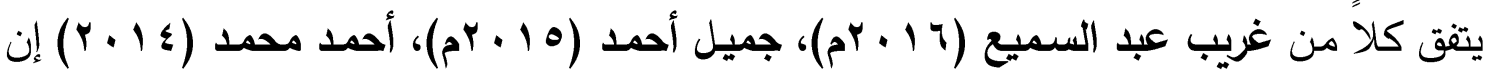
المفهوم الأساسى للعلاقات العامة هو إيجاد التفاهم المتبادل بين المنشآت أو الأفراد القائمين بالعمل فيها، وبين الجماهير المتعاملة معها، فهى تهدف من وراء ذلك إلى إقامـة سمعة طيبة للمنشأة هذا من ناحية والمحافظة على العلاقات الطيبة واستمرار التعامل مع تلك الجماهير من ناحية أخرى. (9: 1 (1)، (0:

ويعرف أشرف صالح (0 1 • rم) العلاقات العامة بأنها هى الجهد المنظم الذى تبذله المنشأة بهدف تحقيق الاندماج مع المجتمع الذى توجد فيه ولا يتحقق ذلك الإندماج إلا بتكييف المنشأة لنفسها مع أهداف المجتمع واحتياجاته ومعاييرة. (ب: 9 (1)

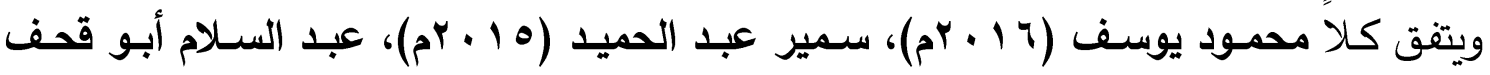
( • ( ب م) يعد المجال الرياضي من المجالات التي تحتاج إلى دعم العلاقات العامة ومؤازرتها. فالرياضة نشـاط يستقطب اهتمامـا جماهيريـا واسعا، وعلى مختلف المستويات، فهناك من يحرص على ممارستها بغية الاستفادة من آثارها الايجابية على صحته وحيويته، وهنالك من يتعلق بها لأنه يشجع ناديا معينا يتابع إخباره ويتتبع مبارياتـه، وهنالك من يعشقها ويتخذ منها مهنـة ويعتبره الناس نجما ويحظى بحب الجمهور واحترامه. وهناك أناس يرتبطون بالرياضـة ارتباطا وثيقا: فأحدهم يعمل بالتـريب، وأخر يشـل 
منصبا في الهيكل الإداري والتتظيمي لفريق معين، وثالث يعمل بالتحكيم الرياضسي. (با: 0ب)، (T: $(\nu \cdot: V) \cdot(\wedge r$

وترى الباحثـة أن الهدف الأساسـي لإدارة العلاقـات العامـة بالأنديـة الرياضـية هو تقويـة وتـدعيم العلاقة بين الأندية وتدعيم العلاقة بين الأندية الرياضية وكافة المتعاملين معها والمشاركين فى تكوينها من خلال وظائفها وأنشطتها التى تعمل على توفير كافة المعلومات والبيانات الخاصـة بدراسـة اتجاهات وآراء تلك الجماهير تجاه النادى والإدارة العليا به ومن أهم هذه العلاقات هى نشر الإعلان والاعلام عن البطولات والمنافسات الرياضية داخل الأندية وتسويقها وايجاد الفرص التى توفر التمويل وتوفر الأموال داخل الأندية الرياضية من هذه البطولات والمنافسات الرياضية.

\section{أهمية البحث والحاجة إليه:}

- تسويق الأحداث والبطولات والمنافسات الرياضية داخل الأندية الرياضية بطرق علمية صحيحة. - ـ استخدام العلاقات العامـة في تسويق الأحداث والبطولات الرياضية داخل الأندية الرياضية لمحاولة توفير أكبر قدر مدكن من الأموال الناتجة من هذا التسويق. هدف البحث:

يهدف هذا البحث إلى دراسة أثر دور العلاقات العامة فى تسويق الأحداث والبطولات الرياضية داخل الأندية الرياضية بدولة الكويت من خلال التعرف على: - الواقع الحالى للعلاقات العامة فى الأندية الرياضية بدولة الكويت. - دور العلاقات العامة في نجاح التظيم للبطولات الرياضية داخل الأندية الرياضية بدولة الكويت. تشاؤلات البحث: - ما هو الواقع الحالى للعلاقات العامة فى الأندية الرياضية بدولة الكويت؟ - مـا هو دور العلاقات العامـة في نجـاح التتظيم للبطولات الرياضـية داخل الأنديـة الرياضية بدولـة الكويتج المصطلحات المستخدمة: - - - العلاقات العامة فى المجال الرباضى: يعرف نيكولاس Nicholas (0 م ـ ام) العلاقات العامة في المجال الرياضي بأنها هي تلك 
الأنثطة التي تستخدم لتكوين علاقات جيدة والمحافظة على هذه العلاقات بين الأندية الرياضية بعضها

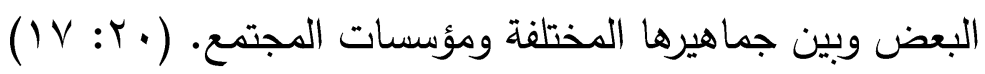
الاراسات السابقة والمرتبطة: 1. الدراسات السابقة والمرتبطة العربية:

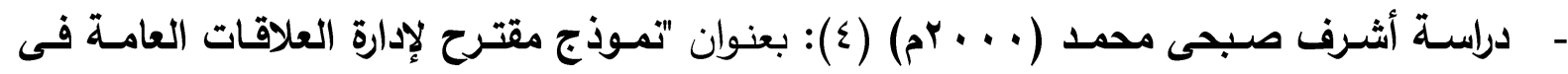
المجال الرياضي". وهدفت هذه الدراسة إلى وضع نظرية للعلاقات العامة فى الإدارة الرياضية معتمدة على بالنظم واتخاذ القرار • وتكونت عينة الدراسة من (r؟r) فرد. واستخدمت الدراسة المنهج الوصفي. ومن أهم نتائج هذه الدراسة أن خمس أختصاصات تسهم فى النموذج المقترح وهى التظيم الإدارى للعلاقات العامة وأهداف العلاقات العامة ووظائف العلاقات العامة والجوانب البحثية للعلاقات العامة و الدور الاستثارى للعلاقات العامة ومساهمتها للإدارة العليا فى اتخاذ القرار .

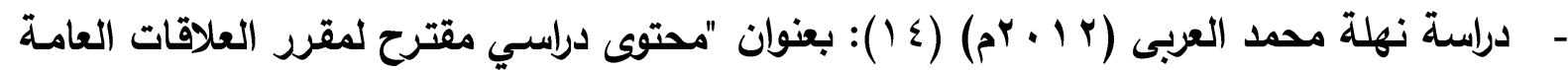
بكليات التربية الرياضية" وهدفت هذه الدراسة إلى التعرف على ما يتم تدريسه عنها وتحليل المحتوى الدراسى لمادة العلاقات العامة واستخدمت الدراسة المنهج الوصفى. ومـن أهم نتائج هذه الدراسـة وضع منهج دراسى لمقرر العلاقات العامة يطبق على طلاب الصف الرابع لثعب الادارة بكليات التربية الرياضية وأوضحت فيه المنهج النظرى المقترح والتوزيع الزمنى لمحتوى المقرر .

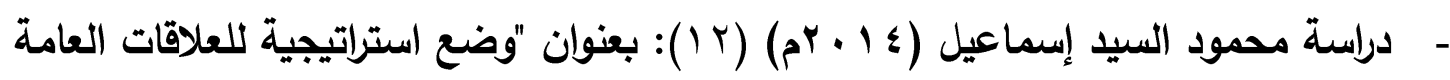
فى الأندية الرياضية بمدن القناة". وتهدف هذه الدراسة إلى التعرف على أهداف العلاقات العامة وتخطيط نشاط العلاقات العامة. وتكونت عينة الدراسة من (ع ب) نادى. واستخدمت الدراسة المنهج الوصفي. ومن أهم نتائج هذه الدراسـة تم وضـع وتحديد أهداف ووظائف وانشطة العلاقت العامة حيث يتم تحقيق الوظائف من خلال الأنثطة التنفيذية للعلاقات العامـة. ويتم انجاز الاهداف من خـلال الانشطة والوظائف و عدم وجود جهاز إدارى مستقل للعلاقات العامـة فى التربية الرياضية

$$
\text { بإدرات الأندية. }
$$

r. الدراسات السابقة والمرتبطة الأجنبية: باسه

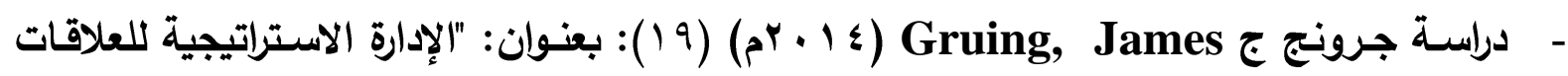

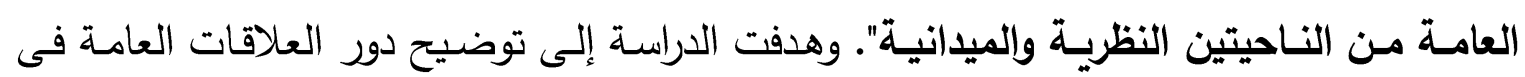


الإدارة الاستراتيجية. وتكونت عينة الدراسـة من (بrr) منظمة فى الولايات المتحدة الامريكية وكندا وأستراليا. واستخدمت الدراسة المنهج الوصفى. ومن أهم نتائج هذه الدراسـة كثفت الدراسة الميدانية عن أن كلاً من رؤساء مجالس إدراات تلك المنظمات يعتقدون أن العلاقات العامة تساهم بشكل كبير فى فاعلية المنظمات من خلال الإدارة الاستراتيجية لمشاركتها فى استراتيجية عمل المنظمات.

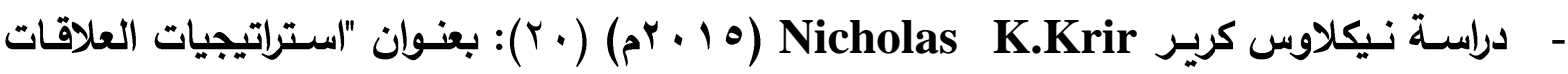
العامـة فـى الجامعةة". وهدفت هذه الدراسـة إلى إيضـاح أهميـة العلاقات العامـة وإدارتها بالجامعات وكيف يمكن إنجاز أهداف المؤسسة والجماهير معاً. وتكونت عينة الدراسة من كليات جامعة البرنا بكندا. واستخدمت الدراسة المنهج الوصفي. ومن أهم نتائج هذه الدارسـة إيضـاح دور ما تقوم بـه استراتيجية العلاقات العامـة بمكتب الشئون العامـة للجامعـة لتحقيق الأهداف وتحديد طبيعة وهويـة الجمـاهير الداخليـة والخارجيـة للجامعـة وكيفيـة التعرف على خصائصـهم وتم وضــع قواعد لتقويم وظائف العلاقات العامة بالجامعة.

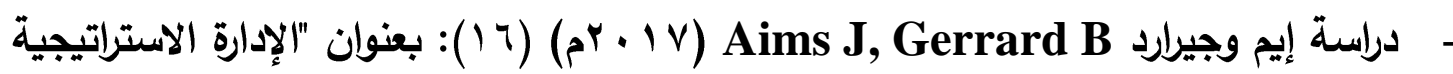
بالمنظمات الرياضية فى مجتمعات أمريكا الثمالية". وهدفت هذه الدراسة إلى التعرف على طبيعة الإدارة الاستراتيجية بالمنظمات الرياضية فى هذه المجتمعات أثناء مؤتمر الإدارة الاستشارى من خلال اقسام الإدارة العامة بتلك المنظمات. وتكونت عينة الدراسة من (ع ا I) مؤسسة رياضية تم اختيارهـا عشوائيا من مجتمعات أمريكا الثمالية. واستخدمت الدراسـة المنهج الوصفى. ومـن أهـم نتـائج هـذه الدارسـة تحتـاج إدارة المؤسسـات الرياضـية إلى بـرامج استراتيجية تتـاسب مـع الفرق الرياضية والأنشطة والخدمات التى تقدمها هذه المؤسسات ويلعب التخطيط الاستراتيجيى دوراً فعالاً لترها فى المؤسسات الرياضية لذا لابد من وضع خطط عامة لبناء قاعدة عريضة من الممارسين.

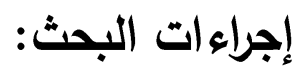
منهج البحث:

استخدمت الباحثة المـهـج الوصـفي متبعـاً الأسـلوب المسحي نظـراً لملائمتهـ لطبيعـة إجـراءات البحث. 


\section{ISSN : YVYัO-\{}

تم إختيار مجتمع البحث من خلال حصر شامل لجميع الأندية الرياضية بدولة الكويت، وإختيار عينة البحث بالطريقة العمدية لجميع الأندية الرياضية بدولة الكويت وعددها (ع () نادي رياضي وبذلك

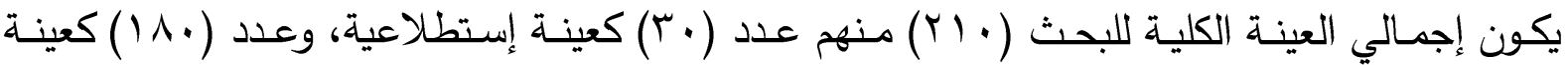
أساسية ويتضح ذلك كما في جدول (1).

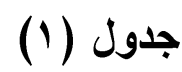

مجتمع وعينة البحث

\begin{tabular}{|c|c|c|}
\hline النسبةٌ المئوية & العينة & البيان \\
\hline$\% 1 \leqslant, r_{q}$ & $(\Gamma \cdot)$ & العينة الاستطلاعية \\
\hline$\% \wedge 0, \vee 1$ & $(1 \wedge \cdot)$ & العينة الأساسية \\
\hline$\% 1 \ldots$ & $(Y) \cdot)$ & المجموع الكلي \\
\hline
\end{tabular}

استبيان دور العلاقات العامـة فى تسويق الأحداث والبطولات الرياضية داخل الأندية الرياضية باولة الكويت (إعداد الباحثة): قامت الباحثة بالإطلاع على العديد من المراجع العلمية والبحوث والدراسات السابقة التي تناولت العلاقات العامة والعلاقات العامة في المجال الرياضي ودورها في ممارسة النشاط الرياضي. قامت الباحثة بوضع المحاور التي توصل إليها في استمارة استبيان وتم عرضها على السادة الخبراء في مجال الإدارة الرياضية والإدارة العامة وعددهم (0) خبراء وبلغ عدد عبارات الاستبيان عدد (9 §) عبارة. قامت الباحثة بعرض استمارة استطلاع رأي الخبراء، وقامت الباحثة بحساب النسبة المئوية لآراء الخبراء.

\section{الاراسة الاستطلاعية:}

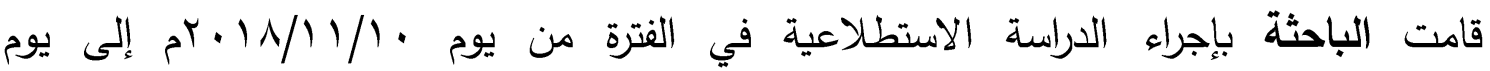

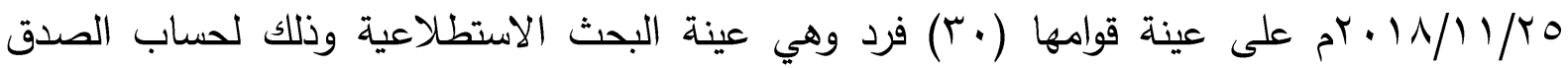


قامت الباحثة بحساب صدق الاستبيان عن طريق حساب معامل الارتباط بين كل عبارة والمحور الخاص بها وبين كل محور من محاور الاستبيان بالدرجة الكلية للاستبيان ككل، كما هو موضح بجدول

\section{جدول (r)}

معامل الارتباط الدال على صدق الاتساق الداخلي لارجة كل محور من محاور الإستبيان بالارجة الكلية للإستبيان

$\mu \cdot=\dot{0}$

\begin{tabular}{|c|c|c|}
\hline 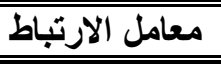 & المحاور & s \\
\hline$*, 019$ & المحور الأول: البطو لات و المنافسات الرياضية داخل النادي الرياضي. & 1 \\
\hline$*_{.}, 001$ & الرياضور الثاني: فاعلية العلاقات العامة فى تسويق البطولات والمنافسات الرياضية داخل النادى & r \\
\hline${ }^{*},, \leqslant 09$ & المحور الثالث: دور العلاقات العامة فى النادي الرياضي. & r \\
\hline${ }^{*} \cdot, 717$ & المحور الرابع: دور العلاقات العامة فى ممارسة النشاط الرياضى. & $\varepsilon$ \\
\hline
\end{tabular}

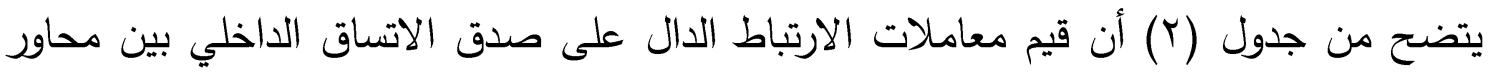

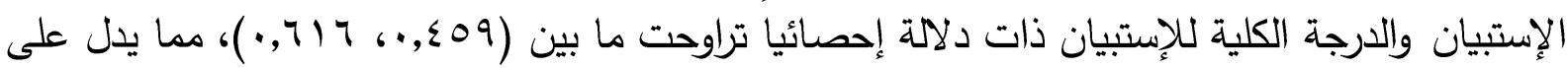
أن جميع المحاور دالة. ثبات الاستبيان:

قامت الباحثة بإيجاد ثبات استمارة الاستبيان عن طريق إعادة تطبيقه مرة أخرى وكان التطبيق الثاني بعد التطبيق الأول بفاصل زمن أسبوعين (10 يوم) ويتضح ذلك كما في جدول(ب).

$$
\text { جدول (r) }
$$

معامل الارتباط بين التطبيق الأول والثاني الدال على ثبات محاور الاستبيان ككل

$\mu \cdot=\dot{0}$

\begin{tabular}{|c|c|c|}
\hline معامل الارتباط & 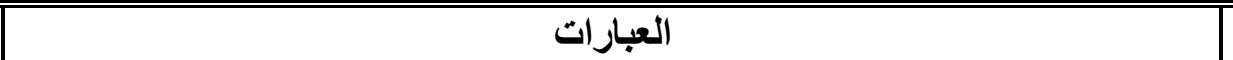 & 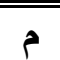 \\
\hline *.,rqr & |المحور الأول: البطو لات و المنافسات الرياضية داخل النادي الرياضي. & 1 \\
\hline$*,, 7) \wedge$ & | المحور الثاني: فالتادلية العلاقات العامة فى تسويق البطولات و المنافسات الرياضية| & $r$ \\
\hline *.,orᄉ & المحور الثالث: دور العلاقات العامة فى النادي الرياضي. & r \\
\hline$* ., 079$ & |المحور الر ابع: دور العلاقات العامة فى ممارسة النشاط الرياضى. & $\varepsilon$ \\
\hline
\end{tabular}




\section{ISSN : YVYัO-\{}

يتضح من الجدول رقم (r) أن قيم معاملات الارتباط الدال على صدق الاتساق الداخلي بين محاور

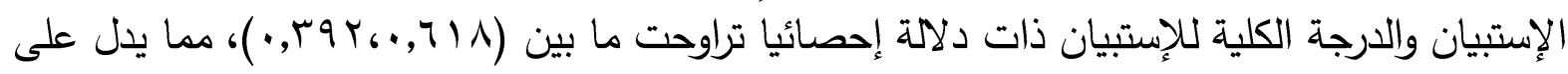
أن جميع المحاور ذات ثبات.

الاراسة الأساسية:

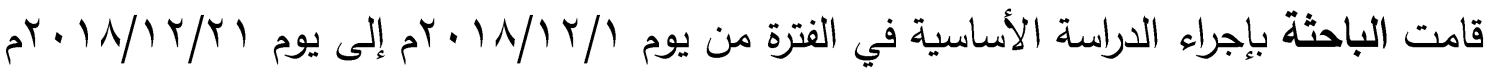
على عينة قوامها ( •11 ) فرد وهي عينة البحث الأساسية. المعالجات الإحصائية:

SPSS تم استخدام المعالجات الإحصائية المناسبة لطبيعة البحث وذلك باستخدام برنامج ( ) ) لإجراء العمليات الإحصائية للبحث.

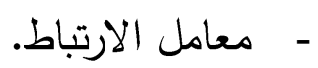
- - معامل ألفا كرونباخ.

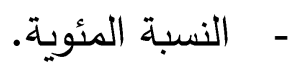

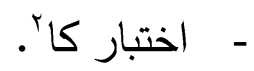

عرض النتائج ومناقشتها: - عرض ومناقشة نتائج المحور الأول: البطولات والمنافسات الرياضية داخل النادي الرياضي:

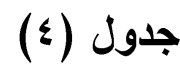

التكرارات والنسب المئوية ومعامل كا' لعبارات المحور الأول البطولات والمنافسات الرياضية داخل النادي الرياضي 11. = ن

\begin{tabular}{|c|c|c|c|c|c|c|c|}
\hline \multirow{2}{*}{ كاי } & \multicolumn{2}{|c|}{ غير موافق } & \multicolumn{2}{|c|}{ إلي حـ مـا } & \multicolumn{2}{|c|}{ موافق } & \multirow{2}{*}{ r } \\
\hline & النسبة المئوية & التكر ارات & النسبة المئوية & التكرار ات & النسبة المئوية & التكر ارات & \\
\hline 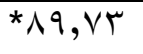 & $\% 70,00$ & 111 & $\%$ \% $\{, \leqslant \leq$ & $\leqslant \varepsilon$ & $\% 1$. & 11 & 1 \\
\hline *ฯ & $\%$ \% ,^^ & ro & $\%$ ro,, 0 & $\leqslant 7$ & $\% 7 \cdot, \infty 0$ & 1.9 & $r$ \\
\hline$* \leqslant \wedge, O r$ & $\%$ & 07 & \% & $r \leq$ & $\% 00,00$ & $1 \cdots$ & r \\
\hline$* V I, Y T$ & $\% 10,00$ & rᄉ & \% & rq & $\% r, v V$ & $11 \pi$ & $\varepsilon$ \\
\hline *qV,Tr & $\% 19, \leq \leqslant$ & ro & \%) & rr & $\% T r, r r$ & 115 & 0 \\
\hline *rr, 9 . & $\% \circ \varepsilon, \leqslant \varepsilon$ & 91 & $\%$ \%,YY & Tr & $\% \uparrow, \wedge \wedge$ & ro & 7 \\
\hline$* q \leq, \leq r$ & $\% T V, r r$ & $|Y|$ & $\% r$ & Tr & $\%$ Ir,VV & אד & $\bar{V}$ \\
\hline 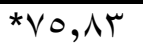 & $\% 19, \leq \varepsilon$ & ro & $\% 17,77$ & r. & $\%$ \% & 110 & 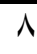 \\
\hline
\end{tabular}




\begin{tabular}{|c|c|c|c|c|c|c|c|}
\hline \multicolumn{2}{|c|}{ ISSN : YVYO-દרIX } & 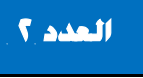 & \multicolumn{2}{|c|}{ الهمبحلة العهبية لملوم آريانسة } & \multicolumn{3}{|c|}{ 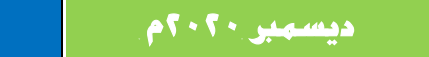 } \\
\hline$* \uparrow \wedge, \cdot r$ & $\%$ \% & $\varepsilon \varepsilon$ & $\% \backslash r, \wedge \wedge$ & ro & $\% 71,77$ & 111 & 9 \\
\hline *Vฯ, Tr & 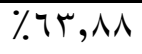 & 110 & $\%(1,11$ & r人 & $\% 10$ & $r V$ & 1. \\
\hline *rr,qr & $\% r r, V V$ & $\leqslant 1$ & $\% 11,77$ & YI & \% & ITY & 11 \\
\hline *09, Y. & $\% 00,00$ & $1 \ldots$ & $\% \wedge, \wedge \wedge$ & 17 & $\%$ \%o,00 & $7 \leq$ & 14 \\
\hline$* \varepsilon r, Y r$ & $\% .00$ & 99 & $\%$ \%q, $\leqslant \varepsilon$ & or & $\% 10,00$ & $r \wedge$ & 11 \\
\hline$* \wedge \wedge, 1 \Gamma$ & זr,r & $\varepsilon r$ & $\% 11,11$ & r. & $\% 70,00$ & 111 & $1 \varepsilon$ \\
\hline
\end{tabular}

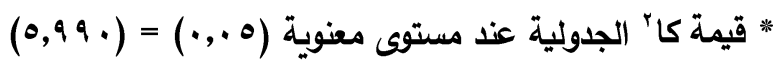
يتضح من جدول (ع) أن هناك فروق ذات دلالة إحصائياً في جميع عبارات المحور لصالح

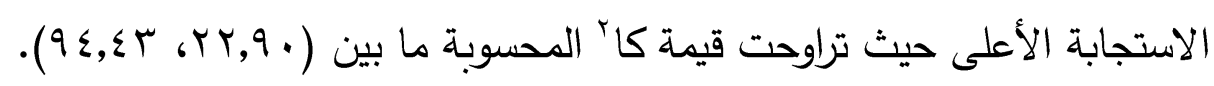

وتوضح الباحثة أن هناك ظاهرة حضارية من قبل شريحة من الثباب ممن هم مرتبطون بمتابعة أخبار ومباريات بعض الفرق، حيث إن الجمهور الرياضي جمهور مثقف رياضياً وملم بكافة الأحداث الرياضية وبصورة ملفتة للانتباه وبالأخص لمتابعة أخبار لعبة كرة القدم وهذا ما أشاد به العديد من النقاد والمختصين في هذا المجال وعلى مختلف الصعد وتقع على عاتق العلاقات العامة بالنادى الرياضى التعريف بموعد وأماكن إقامة البطولات الرياضية والتعريف بالفرق المشاركة فيها.

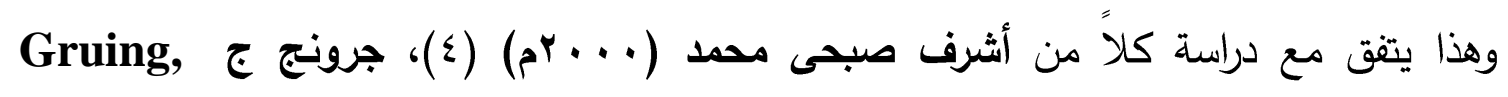
(ع James يكون دوراً ايجابياً يتمثل في دعم الأندية مادياً ومعنويا، وشد أزر النوادي الرياضية. - عرض ومناقثة نتائج المحور الثاني: فاعلية العلاقات العامة في تسويق البطولات والمنافسات الرياضية داخل النادي الرياضي:

جدول (0)

التكرارات والنسب المئوية ومعامل كا` لعبارات المحور الثاني فاعلية العلاقات العامة في تسويق البطولات والمنافسات الرياضية داخل النادي الرباضي

$1 \wedge \cdot=\dot{0}$

\begin{tabular}{|c|c|c|c|c|c|c|c|}
\hline \multirow{2}{*}{ كاי } & \multicolumn{2}{|c|}{ غير موافق } & \multicolumn{2}{|c|}{ إلي حد ما } & \multicolumn{2}{|c|}{ موافق } & \multirow{2}{*}{ r } \\
\hline & النسبة المئوية & التكراراث & النسبة المئوية & التكرارات & النسبة المئوية & التكرارات & \\
\hline * & $\%(1,11$ & "ᄉ & $\% 7 \cdot, 00$ & 1.9 & س & سץ & 1 \\
\hline$* \varepsilon V, \varepsilon \Gamma$ & $\% 07,77$ & $1 . r$ & $\%$ \%V,Yr & $\leqslant 9$ & $\% 17,11$ & $r q$ & $r$ \\
\hline *ץ^,1. & $\%$ \%), & $r q$ & $\% 00$ & 99 & זr,r & $\sum Y$ & $r$ \\
\hline *qr, 1. & $\% T V, Y Y$ & $|Y|$ & $\% I V, Y Y$ & M & $\% 10,00$ & $r \wedge$ & $\varepsilon$ \\
\hline *Yr,qr & \%rr,VV & $\varepsilon 1$ & $\% 11,77$ & YI & \% & ITr & 0 \\
\hline *Yr,qr & $\%$ \% , VV & \&) & $\% 11,74$ & $Y_{1}$ & \% & ITr & 7 \\
\hline
\end{tabular}




\begin{tabular}{|c|c|c|c|c|c|c|c|}
\hline \multicolumn{2}{|c|}{ 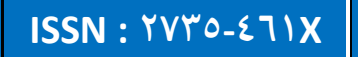 } & آلصدد r & \multicolumn{2}{|c|}{ الهبحلة الملهية لملوم الريلغة } & \multicolumn{3}{|c|}{ 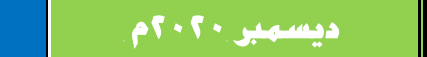 } \\
\hline *ฯ & $\% 7$. & $1 \cdot 1$ & $\% 11,11$ & $r$. & $\% \curlyvee \wedge, \wedge \wedge$ & Or & $V$ \\
\hline$* q \mu, \varepsilon r$ & \% & אץ & $\%) \varepsilon, \varepsilon \varepsilon$ & $r 7$ & $\% T V, Y Y$ & $1 Y 1$ & $\Lambda$ \\
\hline$* Y \vee, q$. & $\% 01,77$ & $9 \pi$ & $\%$ \%1, т & $r q$ & $\%$ & $\xi \lambda$ & 9 \\
\hline$* \leqslant \tau, \cdot r$ & $\%$ \%1, & 07 & 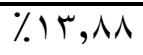 & ro & $\% 00$ & 99 & 1. \\
\hline
\end{tabular}

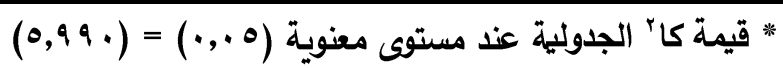

يتضح من جدول (0) أن هناك فروق ذات دلالة إحصائياً في جميع عبارات المحور لصالح

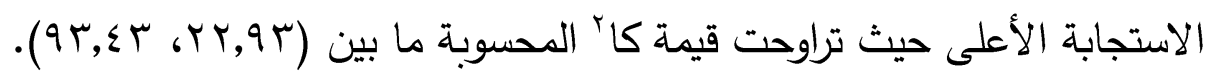

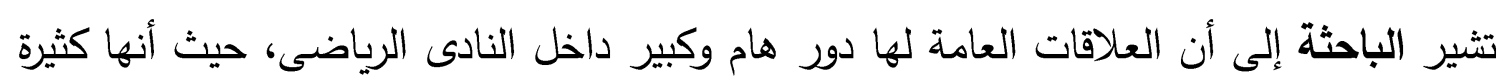

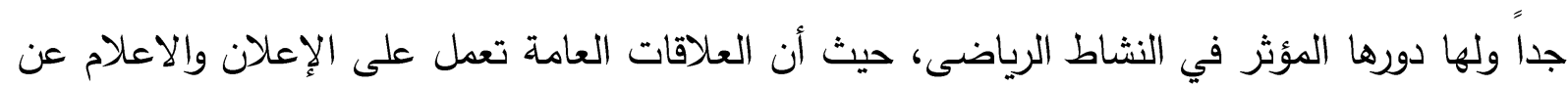

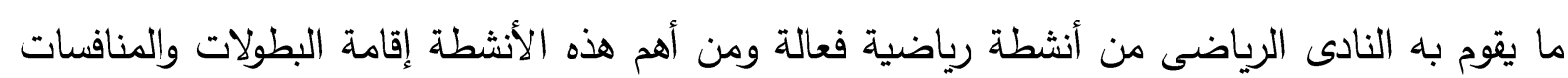
الرياضية والمشاركة بها والتعريف بهذه البطولات والمنافسات.

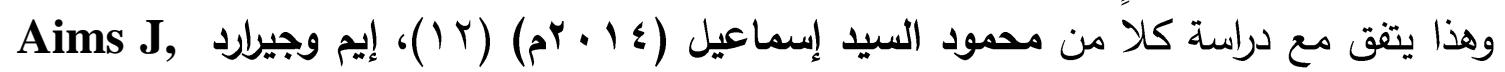

( I Gerrard B المهمة، فلا يكاد يخلو مجتمع من المجتمعات الإنسانية من شكل من أشكال الرياضة وإن الاهتمامات المتزايدة بالرياضة أصبحت تثكل قضايا ومثكلات ذات طبيعة اجتماعية في جوهر. ودور العلاقات العامة فى إدارة النادى الرياضى فهناك العديد من المبادئ الذي تعمل من خلالها العلاقات العامة عند التصدي لإدارة أي أزمة تتشأ فى المجال الرياضى، ومن هذه الرئ المبادئ محدودية الأهداف، الحرص على عدم إحراج الخصم، توسيع نطاق المشاورات، توسيع قاعدة الدعم اللازم للقرار وتعزيز نظام الاتصالات. - عرض ومناقثة نتائج المحور الثالث: دور العلاقات العامة في النادى الرياضي:

جدول (7)

التكرارات والنسب المئوية ومعامل كا؟ لعبارات المحور الثالث دور العلاقات العامة في النادي الرياضي لويات

$11 \cdot=\dot{0}$

\begin{tabular}{|c|c|c|c|c|c|c|c|}
\hline \multirow{2}{*}{ Sاי } & \multicolumn{2}{|c|}{ غير موافق } & \multicolumn{2}{|c|}{ إلي حد ما } & \multicolumn{2}{|c|}{ موافق } & \multirow[b]{2}{*}{ ? } \\
\hline & النسبة المئوية & التكرارات & النسبة المئوية & التكرارات & النسبة المئوية & التكرارات & \\
\hline${ }^{*} \wedge \wedge, 1 \Gamma$ & $\% r r, r r$ & $\varepsilon Y$ & $\% 11,11$ & $r$. & $\% 70,00$ & 111 & 1 \\
\hline$*\rceil \Lambda, \cdot r$ & $\%$ \% $\{\leq \leqslant$ & $\varepsilon \varepsilon$ & $\% \wedge, \wedge \wedge$ & ro & \% & 111 & $r$ \\
\hline$*_{\Delta O r, V H}$ & $\%(r), 11$ & 07 & $\% Y Y, Y Y$ & $\overline{Y Y}$ & $\% 07,77$ & 1.4 & $\Gamma$ \\
\hline
\end{tabular}




\begin{tabular}{|c|c|c|c|c|c|c|c|}
\hline \multicolumn{2}{|c|}{ ISSN : YVYั0-ร7IX } & الصده r & \multicolumn{2}{|c|}{ الهبهلة الصلهية لصلوم الريخسة } & \multicolumn{3}{|c|}{ 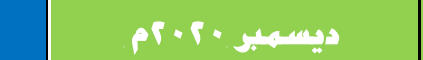 } \\
\hline *rץ,qT & $\%, 1,11$ & rᄉ & $\%$ \%०,00 & \&7 & $\%$ \%r,rr & 97 & $\varepsilon$ \\
\hline$* 10,7$. & $\%$ \%. & $0 \leqslant$ & $\% \Gamma r, r \mu$ & $\varepsilon Y$ & $\%\{7,77$ & $\overline{\lambda \varepsilon}$ & 0 \\
\hline 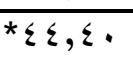 & $\% 07,77$ & $1 \cdot r$ & $\% \Gamma r, r \mu$ & $\varepsilon Y$ & $\%$. & r4 & 7 \\
\hline *r., & $\%$ \%q, $\leqslant \varepsilon$ & 19 & $\% 17,11$ & rq & $\% \Gamma \varepsilon, \varepsilon \varepsilon$ & 74 & $\mathrm{~V}$ \\
\hline *ฯ7,1. & $\% 7 ., 00$ & 1.9 & \%Y, YY & TY & $\% Y V, Y Y$ & $\varepsilon 9$ & $\Lambda$ \\
\hline
\end{tabular}

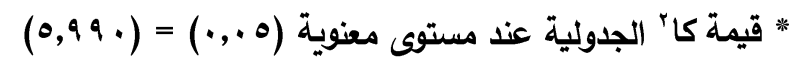

يتضح من جدول (T) أن هنالك فروق ذات دلالة إحصائياً في جميع عبارات المحور لصالح

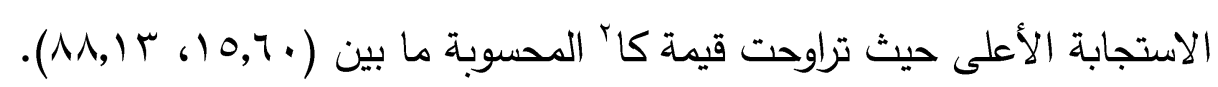

توضح الباحثة أن النشاط الذي تقوم به أجهزة العلاقات العامة بثكل ناجح يؤثر كثيراً بالأنشطة

الأخرى ويتأثر بها. لذلك لا بدّ أن تكون إدارة العلاقات العامة على اتصال دائم ووثيق مع الإدارة العليا للنادى الرياضى، لذا فإن أي نادى رياضى يرغب في الاستفادة القصوى من نشاط العلاقات العامة، عليه أن يجعل موقعها قريباً جداً من الإدارة العليا في الهيكل التنظيمي له وذلك من أجل إتاحة المجال لإدارة العلاقات العامة للنادى الرياضى للمشاركة الفعلية بإتخاذ القرارات الهامة في النادى الرياضى، وفي رسم السياسات العامة لها، والتي تعكس فلسفة النادى الرياضى ومسؤولياته الاجتماعية تجاه فئات الجماهير المختلفة من أجل تحقيق خدمة الجمهور في هذا المجال على أحسن وجه.

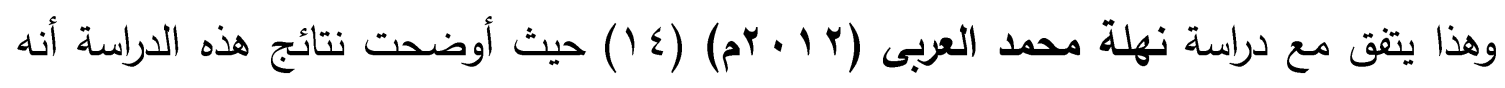
يجب أن يكون هناك تتظيم داخلي للعلاقات العامة والتظيم الداخلي هو عبارة عن التقسيمات الداخلية لإدارة العلاقات العامةالتي تتألف من الوحدات التي تقوم بمجموعها بالنشاطات الداخلية للعلاقات العامة بين جمهور العاملين في المؤسسة. ورغم أنه لا توجد تقسيمات ثابتة لدائرة العلاقات العامةالداخلية إلاّ أن أغلب المؤسسات الكبرى تثكل وحدات متخصصة في المجالات التالية لتغطي بها وظيفة العلاقات العامة

- عرض ومناقشة نتائج المحور الرابع: دور العلاقات العامة في ممارسة النشاط الرياضي:

جدول (v)

التكرارات والنسب المئويـة ومعامل كا` لعبارات المحور الرابع

دور العلاقات العامة في ممارسة النشاط الرباضي

$1 \wedge \cdot=\dot{0}$

\begin{tabular}{|c|c|c|c|c|c|c|c|}
\hline \multirow{2}{*}{ كاr } & \multicolumn{2}{|c|}{ غير موافق } & \multicolumn{2}{|c|}{ إلي حد مـا } & \multicolumn{2}{|c|}{ موافق } & \multirow{2}{*}{ b } \\
\hline & النسبة المئوية & التكرارات & النسبة المئوية & التكرارات & النسبة المئوية & التكرارات & \\
\hline
\end{tabular}




\begin{tabular}{|c|c|c|c|c|c|c|c|}
\hline \multicolumn{2}{|c|}{ ISSN : YVYO-દרIX } & آلصدد r & \multicolumn{3}{|c|}{ الهبحلة آمبهية لملوم آريلشة } & \multicolumn{2}{|c|}{ 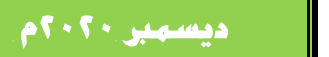 } \\
\hline *Vו, & $\% 10,00$ & rA & $\%$ \% , , & rq & $\% T r, V V$ & $11 \pi$ & 1 \\
\hline *ฯr,V. & $\%$ \%,^ᄉ & ro & $\%$ ro,o0 & $\varepsilon 7$ & $\% 7 \cdot, 70$ & $1 \cdot 9$ & r \\
\hline *Yo, $\Sigma \Gamma$ & $\%(1,11$ & ए人 & $\%$ & 01 & $\%, 0,00$ & 91 & $\Gamma$ \\
\hline${ }^{*} \vee \wedge, \vee$. & $\%$ \% & 117 & $\% 19, \leq \leqslant$ & ro & $\% 17,11$ & rq & $\varepsilon$ \\
\hline$\star \backslash \leq, \wedge$ & \%rY,Yr & $0 \wedge$ & $\%$ \% Y,Yr & $\varepsilon$ & $\% \leqslant 0,00$ & $\Lambda Y$ & 0 \\
\hline * & $\%(1,11$ & rᄉ & $\%$ \% & $\leqslant V$ & $\%$ or, VV & 90 & 7 \\
\hline *) $\varepsilon, 7 r$ & $\%$ \%ท, 11 & 70 & \%乞T,T & $\mathrm{VA}$ & $\% r \cdot, 00$ & rv & V \\
\hline$* q, 1$ & $\% \curlyvee \wedge, \wedge \wedge$ & or & \%rV,rr & $\leqslant 9$ & 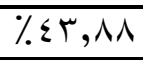 & 19 & $\Lambda$ \\
\hline$* 19, . r$ & $\% \varepsilon \vee, \vee \vee$ & $\wedge 7$ & $\% \mu, 00$ & 00 & $\%$ \%।,TT & $r q$ & 9 \\
\hline *Vo, N & $\% 19, \leq \varepsilon$ & ro & $\% 17,77$ & $r$ & 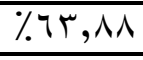 & 110 & 1. \\
\hline$* \varepsilon \wedge, 0 r$ & $\%$ \% & 07 & \% & $r \varepsilon$ & $\% 00,00$ & $1 \cdots$ & 11 \\
\hline *ฯV,Tr & $\% 19, \leq \leq$ & To & \% & r & $\%$ \% T,YY & 114 & IT \\
\hline$* \varepsilon V, r r$ & $\% \curlyvee \wedge, \wedge \wedge$ & or & $\% 10$ & TV & $\% 07,11$ & 1.1 & 11 \\
\hline *V^, V. & $\% 17,11$ & rq & $\% 19, \leq \leq$ & ro & $\%$ \% & 117 & $1 \varepsilon$ \\
\hline
\end{tabular}

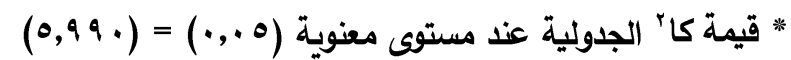
يتضح من جدول (V) أن هنالك فروق ذات دلالة إحصائياً في جميع عبارات المحور لصالح

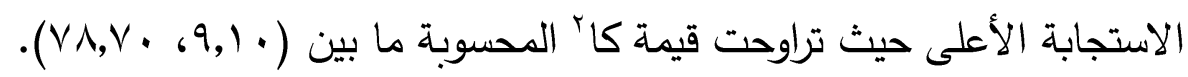
وتوضح الباحثة أن النشاط الذي تقوم به أجهزة العلاقات العامة بشكل ناجح في ممارسة النشاط الرياضى داخل النادى الرياضى يؤثر كثيرا بالأنشطة الأخرى ويتأثر بها. لذا فإن أي نادى يرغب في الاستفادة القصوى من نشاط العلاقات العامة، وذلك من أجل إتاحة المجال لإدارة العلاقات العامة للمشاركة الفعلية بإتخاذ القرارات الهامة في النادى الرياضى، وفي رسم السياسات العامة له، والتي تعكس فلسفته ومسؤولياته الاجتماعية تجاه فئات الجماهير المختلفة من أجل تحقيق أهدافه في هذا المجال على أحسن وجه.

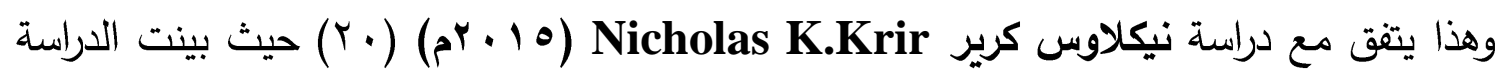
أن لابد من اعداد العلاقات العامة لبرنامج فعال يشتمل على استراتيجيات محددة لتغير اتجاهات الجمهور وصورة المؤسسة لدى افرادها من اجل تحقيق نتائج ملموسة يستطيع من خلالها المؤسسة تحقيق اهدافها وتكوين اتصال قوي بينها وبين وجمهورها والوصول الى صورة ذهنية ايجابية لها.

الاستخلاصات والتوصيات: أولا: الاستخلاصات: فى ضوء أهداف البحث ونتائجه وفى حدود عينة البحث وخصائصها ونتائج المعالجات الإحصائية وبعد عرض ومناقثة النتائج أمكن للباحثة التوصل إلى الاستخلاصاات التالية: 
- - تثارك العلاقات العامة بفاعلية العاملين وأعضاء النادى الرياضى فى مناسباتهم بوفود رسمية. - تعمل العلاقات العامة بتبادل الخبرات والافكار مع الأندية الرياضية الاخرى من خلا استقبال الأعضاء والوفود الزائرة. - تقدم العلاقات العامة بالنادى الرياضى التسهيلات والإشراف المباشر على السفر . ثانياً: التوصيات:

فى حدود عينة البحث وفى ضوء النتائج التى توصلت إليها الباحثة توصى الباحثة بالأتى: - - بذل الجهود من قبل إدارة الانشطة الرياضية وإدارة النادى الرياضى للعمل على تفعيل إقامة البطولات والمنافسات الرياضية، ودراسة سبل التفعيل التى تم التوصل إليها. - - ضرورة تطوير مفهوم العلاقات العامة لاى النادى الرياضى وفقا للتطور الحاصل فى تكنولوجيا الاتصالات والمعلومات لذا يجب أن تتصب جهود النادى الرياضى نحو الإهتمام بالعلاقات العامة

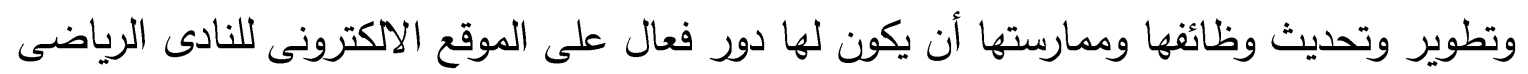
وهذا يؤكد على ضرورة تعلم وتطبيق ممارسى العلاقات العامة وسائل التكنولوجيا الحديثة فى ممارساتهم لوظائفهم. - - تحديد الانشطة الاساسية للعلاقات العامة تحديدا دقيقا واسنادها الى أجهزة العلاقات العامة وفقا للتخصصات الموجودة دون اسناد أى أنشطة أو أعمال ليست من إختصاصات العلاقات العامة. - أن تعمل العلاقات العامة ضمن برامجها الإتصالية على تتمية الشعور بالفخر والإعتزاز لاى إلى العاملين بإنتمائهم للنادى الرياضى.

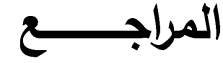

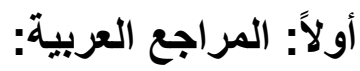

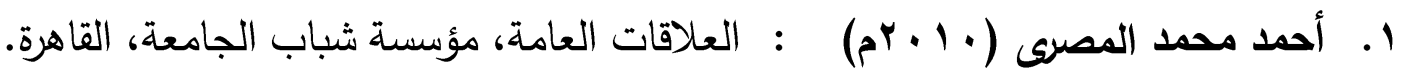

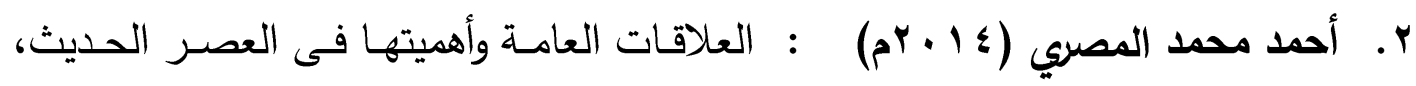
مؤسسة شباب الجامعة، الإسكندرية.

: : تصميم المطبوعات الإعلامية، طابك، القاهرة.

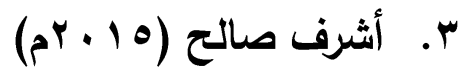

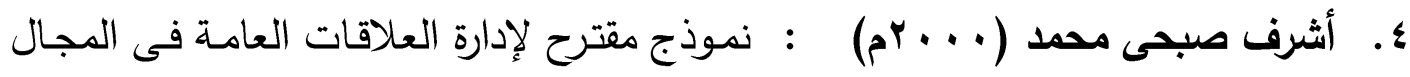


الرياضــى، دراسـة دكتـوراة، غيـر منشـورة، كليـة

التربية الرياضية للبنين جامعة حلوان، القاهرة.

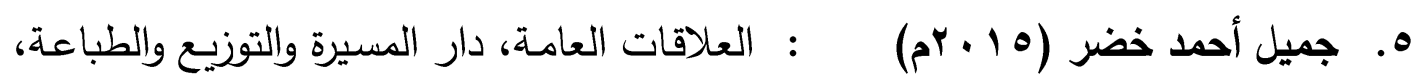
عمان.

: الأعلام والعلاقات العامة في المجال الرياضي.

7. سمير عبد الحميد على

$\left(b^{2} \cdot 10\right)$

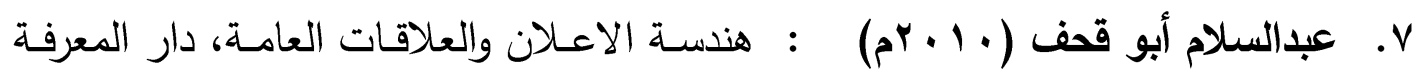

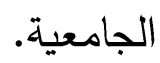

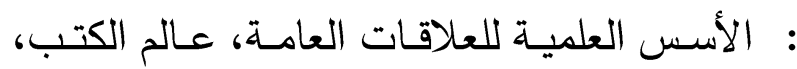

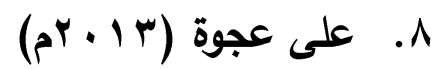

القاهرة.

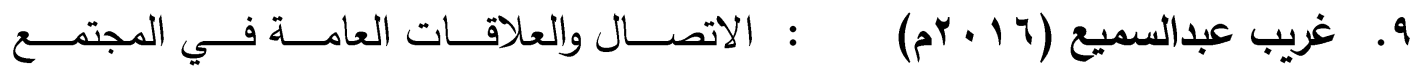

المعاصر ، مؤسسة شباب الجامعة، الإسكندرية.

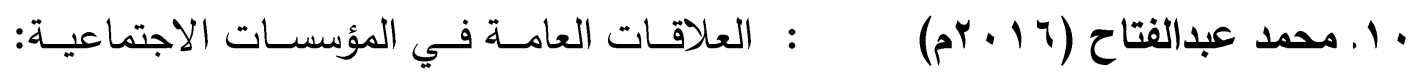
اسس ومبادئ" المكتب العلمي للكمبيوتر والنشر ،

$$
\text { الإسكندرية. }
$$

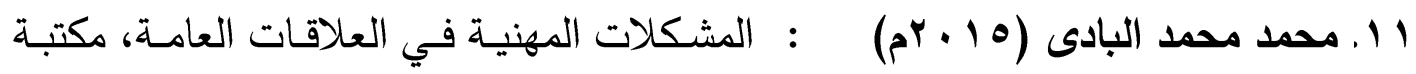
الأنجلو المصرية، القاهرة.

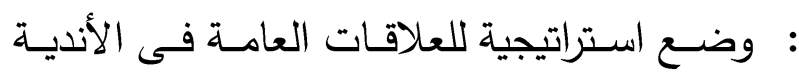
الرياضـية بمـدن القنـاة، رسـالة ماجسـتير غيـر r 1 . محمود السيد إسماعيل $(a r+1 \varepsilon)$

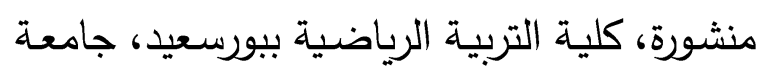
قناة السويس. : العلاقـات العامـة في المجـال التطبيقـي، توزيـع الدار العربية النشر والتوزتح. با 1 . محمود يوسف مصطفى $\left(a^{r} \cdot 17\right)$ : محتوى دراسـي مقترح لمقـرر العلاقـات العامـة،

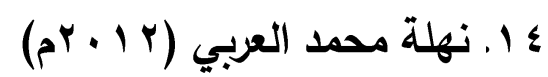
بكليات التربيـة الرياضـية، رسـالة ماجتسير غير منشورة، كلية التربية الرياضية، جامعة أسيوط. : تــأثير الاســتعدادات الخاصـــة لــدى العــاملين ه 1 . وفاء صلاح عبدالرحمن بالعلاقـات العامـة على أدائهـم المهنـى، رسـالة $(a r+1 v)$ 


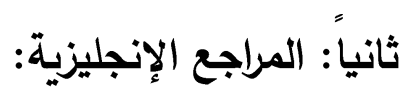

17. Amis J. Gerrard B, : The Strategic management of sport Maaws M, Slack T, organizations, (NASSM) abstracts, Mason, D. $(r \cdot I V)$ available at.

iv. Bronson, R.T : Public relations and promotion in $(r+10)$ sport, U.S. sport Academy.

1^. Cutlips, Allen C \& : Effective public relations Engle wood, Gelen Broon $(\uparrow \cdot 1 \leqslant)$ prentice hall, New Jersey.

19. Gruning, James, P. : Rin Strategic management and $(r+1 \varepsilon)$ strategic management of P.R, Faculty of Humanities and social sciences, united Arab Emirates, University, Alain.

r.. Nicholas K. Krir, : Strategies case study unpublished P.R. $(r+10)$ master degree, university of Alberta Canadian, Edition. 